LOPES, V. Análise de uma objeto de aprendizagem na perspectiva da teoria da aprendizagem significativa: o professor diante da possibilidade de transformação

\title{
ANÁLISE DE UM OBJETO DE APRENDIZAGEM NA PERSPECTIVA DA TEORIA DA APRENDIZAGEM SIGNIFICATIVA: O PROFESSOR DIANTE DA POSSIBILIDADE DE TRANSFORMAÇÃO
}

Verônica Lopes ${ }^{1}$

\section{RESUMO}

Este artigo tem como objetivo apresentar uma das atividades implementadas em uma pesquisa de campo realizada no Mestrado Profissional em Educação Matemática da Universidade Federal de Ouro Preto (UFOP). Diante das características do trabalho e da formação inicial do professor de Matemática na sociedade da informação, vislumbramos a necessidade de uma formação continuada sobre o uso de Objetos de Aprendizagem na perspectiva da Teoria da Aprendizagem Significativa. Realizamos um processo de formação continuada por meio do qual desenvolvemos uma pesquisa de abordagem qualitativa. Descrevendo uma das atividades dessa formação, que se constitui na análise de um Objeto de Aprendizagem na perspectiva da Teoria da Aprendizagem Significativa, discute-se a postura do professor diante da possibilidade de transformação. Finalmente, concluímos que alguns docentes permanecem resistentes e atuando com uma prática tradicional, enquanto outros se sentem propícios às mudanças, desafiam-se às diferentes maneiras de ensinar e notam contradições entre suas práticas e o novo saber.

Palavras-chave: Objetos de aprendizagem. Teoria da aprendizagem significativa. Formação continuada. Educação Matemática. Transformação.

\section{ANALYSIS OF A LEARNING OBJECT IN PERSPECTIVE THEORY OF SIGNIFICANT LEARNING: TEACHER AGAINST THE POSSIBILITY OF TRANSFORMATION}

\begin{abstract}
This article has the objective of to present one of the activities implemented in the research field of the Professional Masters in Mathematics Education, Federal University of Ouro Preto UFOP. Against the characteristics of the work and initial training of mathematics teachers in the information society, we perceive the need for continued training about the use of learning objects in view of the Theory of Meaningful Learning. We realize a process of continuous formation through which we develop a qualitative research. Describing one of the activities of this training, which is the analysis of a learning object in view of the Theory of Meaningful Learning, is discussed the teacher's attitude towards the possibility of transformation. Finally, we conclude that some teachers remain resistant and acting with a traditional practice, while others feel conducive to change, challenge yourself to different ways of teaching and note the contradiction between their practices and the new knowledge.
\end{abstract}

\footnotetext{
${ }^{1}$ Mestre em Educação Matemática pela Universidade Federal de Ouro Preto (UFOP), professora pesquisadora da UFOP/CEAD e professora do Instituto Federal de Minas Gerais - Campus Governador Valadares. E-mail: veronica.lopes@ifmg.edu.br.
} 
LOPES, V. Análise de uma objeto de aprendizagem na perspectiva da teoria da aprendizagem significativa: o professor diante da possibilidade de transformação

Keywords: Learning objects. Theory of meaningful learning. Continuing education. Mathematics education. Transformation.

\section{INTRODUÇÃO}

Neste artigo, apresentamos um recorte da nossa pesquisa realizada no âmbito do Mestrado Profissional em Educação Matemática da Universidade Federal de Ouro Preto (UFOP). Descrevemos aqui uma das atividades realizadas em nossa pesquisa de campo, na qual um grupo de professores analisou o objeto de aprendizagem (AO) "Geometria da Cidade" na perspectiva da Teoria da Aprendizagem Significativa (TAS) e, diante da análise dessa atividade e de suas consequências, discutimos a postura do professor diante da possibilidade de transformação em relação aos seus conhecimentos e práticas.

A publicação deste artigo se justifica pela importância e necessidade de compartilhar com outros leitores, possivelmente professores de Matemática e/ou formadores de professores, estratégias que poderão ser utilizadas por esses profissionais para construir conhecimento sobre o uso de um recurso tecnológico fundamentado teoricamente e trazer contribuições para a sua prática pedagógica. Com este artigo pretendemos criar condições para que nossa pesquisa chegue até a sala de aula e possíveis avanços aconteçam no ensino de Matemática.

Nossa pesquisa se justifica ante a realidade que delineamos a seguir. A educação está inserida em um novo contexto: a sociedade da informação. Esse paradigma é alicerçado pelas Tecnologias da Informação e Comunicação na Educação (TICE's), o que engendra novas maneiras de ensinar e aprender e uma transformação nas práticas do professor e do aluno. Essa nova realidade exige que o professor vivencie a utilização dos recursos tecnológicos educacionais em suas aulas. Porém, o uso de TICE's, por vários motivos, principalmente devido às características do trabalho e da formação inicial do professor, ainda é uma realidade fora do alcance da grande maioria dos docentes, o que torna premente a participação desse profissional em processos de formação continuada. Concebemos, portanto, a formação continuada como um caminho para a orientação de um trabalho com os Objetos de Aprendizagem na perspectiva da Teoria da Aprendizagem Significativa.

Motivados por essa realidade e por nossas vivências acadêmicas e profissionais, decidimos pesquisar quais as contribuições para o professor de Matemática, relativas às aprendizagens e a uma natureza propícia às mudanças advindas do processo de formação continuada sobre "Objetos de Aprendizagem na perspectiva da Teoria da Aprendizagem Significativa". 
LOPES, V. Análise de uma objeto de aprendizagem na perspectiva da teoria da aprendizagem significativa: 0 professor diante da possibilidade de transformação

Para tanto, realizamos uma formação continuada com professores ${ }^{2}$ de Matemática da Rede Municipal de Ensino de Ipatinga - MG, cujo processo durou cinco meses, compreendendo encontros presenciais (atividades mensais) e à distância (atividades semanais realizadas na plataforma Moodle). Por meio desse processo, desenvolvemos uma pesquisa com o método de investigação de abordagem qualitativa, que entendemos mais adequada para estudar as relações que ocorrem nos processos de mudança e aprendizagem vivenciados pelos docentes.

Neste artigo - um recorte da nossa pesquisa de mestrado - nosso objetivo é analisar como os professores mostraram-se diante da possibilidade de transformação em relação aos seus conhecimentos e práticas. Para isso, procuramos identificar indícios de uma natureza propícia ou não à transformação, a partir do momento em que os professores vivenciaram a atividade de análise de um OA na perspectiva da TAS no processo de formação continuada.

A discussão da postura do professor diante da possibilidade de transformação foi realizada a partir dos dados registrados no diário de campo, nos questionários de perfil inicial e final, nas atividades realizadas à distância e nos encontros presenciais, e na avaliação do professor, estabelecendo uma relação entre os dados coletados e a literatura estudada para a elaboração deste trabalho.

Para descrever de forma clara esse processo, a estrutura deste artigo é composta por quatro partes: essa introdução; a fundamentação teórica sobre os Objetos de Aprendizagem, a Teoria da Aprendizagem Significativa e sua ressonância com os OA's, e sobre o professor e a possibilidade de transformação; a descrição da atividade realizada, sua análise segundo a TAS e as consequências dessa experiência; a conclusão, na qual discutimos algumas características do processo de transformação docente diante de atividades que vão de encontro com a prática que ele está acostumado a repetir.

\section{FUNDAMENTAÇÃO TEÓRICA}

\subsection{O Objeto de Aprendizagem}

\footnotetext{
${ }^{2} \mathrm{O}$ grupo de participantes da pesquisa foi constituído por professores de Matemática, iniciando com 55 pessoas, cuja presença foi variando no decorrer do processo. Todos são professores de Matemática do $6^{\circ}$ ao $9^{\circ}$ ano do Ensino Fundamental, da Rede Municipal de Ensino de Ipatinga - MG, sendo contratados ou efetivos. Consideramos que o grupo interessado a participar da pesquisa possuía um número muito bom, frente a um total de cerca de 70 professores da rede, os quais foram todos convidados. Como se tratava de um convite, os professores, que não se interessaram em participar da formação, poderiam cumprir seu horário livremente em sua escola, realizando o planejamento semanal de suas atividades.
}

ForSci.: r. cient. IFMG campus Formiga, Formiga, v. 3, n. 1, p. 87-103, jan./jun. 2015 
LOPES, V. Análise de uma objeto de aprendizagem na perspectiva da teoria da aprendizagem significativa: o professor diante da possibilidade de transformação

No processo de formação continuada, estudamos com os professores, o conceito, as limitações e as potencialidades dos objetos de aprendizagem. Segundo Domenico et. al (2006), não há um conceito de objeto de aprendizagem aceito universalmente; talvez, por este ser um campo de estudo relativamente novo. No meio de diversas definições, essa é a que abraçamos: objeto de aprendizagem é "[...] qualquer recurso digital que pode ser reutilizado para suportar a aprendizagem" (WILEY, 2000, p. 3)

Ao elucidar o significado de suporte, notamos que os OA's, definidos como suporte da aprendizagem, podem oferecer condições para a promoção de uma aprendizagem significativa.

Como são digitais e interativos, os OA's compreendem áudios, vídeos, hipertextos, links, simulações, animações, calculadoras eletrônicas, softwares, que servem para desenvolver o conhecimento. Eles são ferramentas digitais que tentam solucionar, de maneia tímida, o problema da ausência das novas tecnologias nas escolas. Ressaltamos que a falta das TICE's nas escolas e as dificuldades do trabalho com essas ferramentas pelos docentes representam as situações reais das escolas e dos professores, frutos da ausência de investimento em novas tecnologias na educação e da formação docente. É nesse contexto que os OA's, sendo de fácil utilização e não necessitando de conhecimentos técnicos específicos para o seu uso, tentam minimizar esses problemas na realidade escolar.

A maioria dos OA's vem acompanhada de um guia do professor. Esse guia é um material pedagógico que auxilia no planejamento do uso de um OA, contendo explicações dos recursos disponíveis e sugestões de atividades a serem realizadas antes, durante e depois dos experimentos. Cada professor decide como usar o OA em sua aula, de acordo com o perfil de sua turma e os objetivos propostos, com total liberdade e sem depender de estruturas rígidas. Assim, é possível usá-lo como um todo ou apenas algumas de suas atividades. Se porventura um OA não vier acompanhado de seu guia, esse poderá ser produzido pelo próprio docente, após a análise e experiência com esse OA.

Uma questão importante, que raramente tem sido comentada nos artigos sobre OA, é o motivo pelo qual eles são assim denominados. Por uma razão nobre esses instrumentos foram nomeados objetos de aprendizagem: seu foco está no aprender e não no ensinar (MACHADO; SÁ FILHO, 2003). Machado e Sá Filho (2003) afirmam que, mesmo sendo subjetiva a classificação de um objeto, existe uma perda de eficácia ao se utilizar objetos de ensino como se fossem de aprendizagem. Na visão dos autores, um objeto que apenas apresenta uma informação, mesmo com um objetivo educacional, deve ser chamado de objeto de ensino. Para um objeto ser denominado de objeto de aprendizagem, deve ser interativo e estimular a reflexão 
LOPES, V. Análise de uma objeto de aprendizagem na perspectiva da teoria da aprendizagem significativa: o professor diante da possibilidade de transformação

do aluno, permitindo-lhe refletir sobre a reação do objeto, desequilibrando os conhecimentos já construídos pelo aluno em busca de novos, num processo de construção do saber (DOMENICO et. al, 2006).

É de suma importância compreender essas diferenças para se trabalhar com eficiência com os OA's, pois caberá ao professor ter uma visão crítica para escolher o OA a ser utilizado. Até mesmo porque muitos OA's disponíveis não têm como preocupação, no momento de sua elaboração, a aprendizagem ao invés do ensino. É apenas uma pequena classe no universo dos OA's que segue essa perspectiva.

Em nossa pesquisa, nossas ações visaram problematizar o processo de escolha de OA's pelo professor para seu trabalho em sala de aula, buscando aqueles que priorizam a construção do conhecimento pelo aluno. Para isso, no processo de formação continuada, analisamos os OA's na perspectiva da TAS, a qual descrevemos no tópico seguir.

\subsection{A Teoria da Aprendizagem Significativa: ressonância com os Objetos de Aprendizagem}

“Aprender de maneira significativa é aprender com significado" (MASINI; MOREIRA, 2008, p. 9). A aprendizagem significativa é aquela em que o significado do novo conhecimento é adquirido, construído com compreensão e por meio da interação não-arbitrária e não literal desse novo conhecimento com algum conhecimento prévio relevante existente na estrutura cognitiva do aprendiz. É a aquisição de conhecimentos com compreensão e elaboração, com maior retenção, com capacidade de explicação, aplicação e transferência (MASINI; MOREIRA, 2008). A aprendizagem é significativa quando se vê sentido nas situações de aprendizagem e atribui-se significado a elas.

Segundo Ausubel (2003), a interação é a essência ou o núcleo do processo de aprendizagem significativa. As novas informações não apenas se associam, mas interagem com os conhecimentos prévios relevantes e ambos se modificam num processo de transformação mútua. Ser não-arbitrária significa que o novo conhecimento não interage com qualquer conhecimento prévio, mas com um que seja relevante. A característica não literal indica possuir significados pessoais, incorporar a substância do novo conhecimento, e não as palavras usadas para expressá-lo.

A primeira condição e ponto de partida para a ocorrência da aprendizagem significativa é a existência de conhecimentos prévios relevantes (AUSUBEL, 2003). Conhecimento prévio 
LOPES, V. Análise de uma objeto de aprendizagem na perspectiva da teoria da aprendizagem significativa: o professor diante da possibilidade de transformação

é um conceito, ideia, proposição, representação, imagem ou modelo. É o fator isolado mais importante e a variável que mais influencia na aprendizagem. É necessário ter conhecimentos prévios adequados, relevantes, diferenciados de outras ideias semelhantes, e disponíveis na estrutura cognitiva para atribuir significado à nova informação. Dessa forma, o conhecimento prévio relevante, chamado de subsunçor, servirá de ancoradouro para o novo conhecimento.

Outra condição é a predisposição para aprender (AUSUBEL, 2003). Ela não é motivação, mas implica motivação. É uma intencionalidade, um esforço deliberado, é o foco para onde se dirigem nossos estados mentais. É um compromisso, não no sentido de gostar, mas de querer.

A terceira condição é o material potencialmente significativo (AUSUBEL, 2003). Ser potencialmente significativo implica dizer que tenha significado lógico, ou seja, é o mesmo que oferecer suporte para que o conteúdo seja aprendido por quem tem conhecimento prévio relevante e adequado e se dispõe a aprendê-lo.

Para facilitar a aprendizagem significativa, "não há receitas, mas há estratégias" (MASINI; MOREIRA, 2008, p. 36). O principal recurso facilitador da conceitualização, devido a sua característica de ser mediadora, é a linguagem (AUSUBEL, 2003). Ela é um instrumento imprescindível para a interação pessoal, discussão e negociação de significados.

Outra estratégia facilitadora é relacionar o que aluno está aprendendo na escola com o seu dia a dia, fazendo uma ponte entre o conhecimento científico e o mundo em que ele vive (AUSUBEL, 2003).

Os organizadores prévios são um recurso facilitador, correspondendo a materiais instrucionais introdutórios e mais inclusivos, que funcionam como mecanismo pedagógico e são apresentados antes do conteúdo a ser aprendido (AUSUBEL, 2003). Podem ser textos escritos, filmes, uma discussão ou demonstração. Eles têm como objetivo desenvolver conceitos subsunçores que facilitem a aprendizagem, construindo uma "ponte cognitiva" entre o que o aluno sabe e o que deveria saber, ou ajudá-lo a relacionar o novo conhecimento com o seu conhecimento prévio.

Refletindo sobre as tecnologias e a aprendizagem, pode-se afirmar que é possível existir uma harmonia entre certa pedagogia e uma mídia, pois “[ ...] as mídias informáticas associadas a pedagogias que estejam em ressonância com essas novas tecnologias podem transformar o tipo de Matemática abordada em sala de aula" (BORBA; PENTEADO, 2010, p. 38). Masetto (2000, p. 139) concorda com essas ideias ao afirmar que: “[...] é impossível dialogarmos sobre tecnologia e educação, inclusive educação escolar, sem abordarmos a questão do processo de 
LOPES, V. Análise de uma objeto de aprendizagem na perspectiva da teoria da aprendizagem significativa: o professor diante da possibilidade de transformação

aprendizagem." Portanto, a teoria de aprendizagem que fundamenta nossas ações poderá nos ajudar a pensar como o conhecimento construído pelos alunos será mediado com o uso das novas tecnologias.

É necessário, então, pensarmos no OA como um reflexo da concepção de conhecimento na qual nos baseamos, que é a TAS, estabelecendo, assim, conforme argumentam Borba e Penteado (2010), uma "ressonância" entre a TAS e os OA's. Caberá ao professor ter conhecimento para escolher o OA a ser trabalhado, a fim de que a ferramenta utilizada evidencie as condições de ocorrência e os recursos facilitadores da aprendizagem significativa.

\subsection{O professor e a possibilidade de transformação}

A partir da premissa de que o professor deve saber escolher um OA que priorize a aprendizagem, nossa proposta de formação não se limitou à experiência de inserção do computador nas aulas de Matemática, mas foi além; preocupou-se com a formação de um professor que saiba avaliar o recurso tecnológico (OA) para poder escolhê-lo, refletir as melhores maneiras de utilizá-lo, e as possíveis implicações dessa ação na sua prática pedagógica. Portanto, o maior desafio não está na instrumentação técnica, mas nas formas produtivas e viáveis de se utilizar as TICE's nos processos de ensino e aprendizagem, no currículo vigente, nas situações reais dos professores e da escola (KENSKI, 2007).

Além disso, em nossa formação, discutimos com os professores sobre a postura docente adotada no trabalho com as TICE's. Alguns professores concentram sua atuação, na sala de aula, numa "zona de conforto", onde se conhece tudo, limitando-se ao previsível. Segundo Masetto (2000, p. 142), sair da zona de conforto gera um grande desconforto e uma insegurança nos professores. Esses não avançam para a chamada "zona de risco", onde a tecnologia está presente e onde, portanto, se trabalha com desafios, novas situações, o imprevisível e a perda de controle (BORBA; PENTEADO, 2010).

Logo, os atores educacionais precisam adotar uma prática que tenha como base a visão crítica em relação ao uso dos recursos tecnológicos disponíveis para a aprendizagem, conforme Guérios (2005, p. 146) afirma:

A perspectiva inovadora da prática pedagógica não reside na aplicação pura e simples de uma nova técnica de ensino, mas sim na postura diferenciada que o professor e os alunos apresentam em relação ao conhecimento. Uma postura interrogativa, questionadora, investigativa, exploratória e de produção e negociação de sentidos perante o saber. 
LOPES, V. Análise de uma objeto de aprendizagem na perspectiva da teoria da aprendizagem significativa: 0 professor diante da possibilidade de transformação

Quando se tem uma concepção pedagógica que orienta o trabalho com as TICE's de maneira crítica, existe a possibilidade de se alterarem os papeis do professor e do aluno. Por meio de uma ação pedagógica renovada, o foco atual do professor passa a ser a aprendizagem com base interdisciplinar e tem como desafio superar a fragmentação e a reprodução para promover a produção do conhecimento. Nessa perspectiva, o eixo de sua ação transita do ensinar para o "aprender a aprender". Elimina sua autoridade de dono da verdade, para tornarse pesquisador, questionador, investigador crítico e reflexivo. Sua prática, que antes se fundamentava no "paradigma fordista", se restringia em "empurrar" a informação ao aluno; nesse novo contexto, implica em criar situações em que o aluno "puxe" a informação, num processo de resolução de problemas significativos e reflexão sobre os resultados obtidos (VALENTE, 1999).

Por meio dessa nova ação, o professor se torna um mediador/orientador, facilitador, que motiva, estimula, problematiza e ajuda os alunos a interpretar as informações, relacioná-las e contextualizá-las, oferecendo uma orientação intelectual, emocional e gerencial. O professor age para que as novas informações se tornem significativas para os alunos, possibilitando que eles as compreendam, reelaborem-nas e adaptem-nas aos seus contextos pessoais.

Diante desse contexto de necessidade de transformação, as propostas de formação continuada consideram como ponto de partida e de chegada da prática cotidiana do professor, a fim de buscar soluções para seus problemas, para suas necessidades e aperfeiçoamento de sua prática.

Guérios (2005) destaca os elementos fundamentais num processo de formação: o trabalho coletivo, a aprendizagem de novos referenciais teóricos e práticos, a necessidade de novas experiências didáticas a partir de inovações metodológicas e a reflexão permanente e sistemática antes, durante e após as experiências vivenciadas. Utilizando esses elementos, pretendemos que o professor vivencie processos de aprendizagens e mudanças, de diferentes naturezas, pois, segundo Baldino (1999), a mudança é a aposta para extinguir o fracasso do ensino da Matemática, seja a mudança na escola, na sala de aula, no aluno e no professor.

Ponte e Serrazina (2004, p. 32) afirmam que essa formação "pode contribuir para a mudança de concepções, mas essas não ocorrem somente no quadro de processos de formação". Segundo esses autores, o crescimento do professor não resulta de uma única intervenção, mas é um processo evolutivo lento que exige a vinculação de vários aspectos, como mudanças organizacionais, a relação dos professores com os conteúdos que ensinam e a indispensável formação. Mudanças acontecem em um processo difícil, lento e penoso, enfrentando problemas 
LOPES, V. Análise de uma objeto de aprendizagem na perspectiva da teoria da aprendizagem significativa: o professor diante da possibilidade de transformação

e resistências no meio do caminho. Essas mudanças, então, dependem de todo um contexto geral.

No bojo dessas ideias, reconhecemos as limitações da formação continuada, mas também a sua importância, o que agudiza ainda mais o nosso desejo de contribuir de maneira extremamente responsável por meio da nossa proposta de formação continuada, na qual realizamos uma importante atividade que passamos a descrever a seguir.

\section{ANÁLISE DE UMA ATIVIDADE REALIZADA}

Enquanto pesquisadora no planejamento das atividades da formação, após a análise que fizemos de alguns OA's disponíveis que abordam o tema Geometria para o Ensino Fundamental, fundamentada nas condições de ocorrência da aprendizagem significativa e nos recursos que podem facilitá-la, selecionamos três OA's para serem manipulados e analisados pelo professores com base na Teoria da Aprendizagem Significativa.

A manipulação dos OA's foi feita em duplas, sem nenhum conhecimento anterior dos professores sobre o recurso. A intenção foi de que, primeiramente, os professores manipulassem um OA sem nenhuma explicação anterior e que, posteriormente, numa próxima atividade da plataforma Moodle, manipulassem novamente o mesmo OA após a leitura e análise do Guia do Professor, a fim de avaliar as contribuições desse instrumento para o trabalho com esses objetos.

Analisamos em um dos encontros, de forma coletiva, o OA Geometria da Cidade $^{3}$, e os outros OA's foram analisados no decorrer do mês por meio das atividades disponibilizadas na plataforma Moodle. Questionamos os professores se o OA Geometria da Cidade possuía atividades e/ou características que contemplavam as condições de ocorrência da aprendizagem significativa, como o conhecimento prévio, a predisposição em aprender e o material potencialmente significativo.

Sobre o conhecimento prévio, os professores comentaram que a primeira atividade trabalha com esse conhecimento do aluno ao solicitar que contemplem as formas geométricas encontradas na cidade do OA que se relaciona com a realidade de seu bairro e/ou cidade, como a praça, os prédios e o guarda-sol. A respeito da predisposição em aprender, foi relatado que o OA implica motivação porque ele trabalha com questões que fazem parte do dia a dia do aluno,

\footnotetext{
${ }^{3}$ Endereço do OA "Geometria da cidade": Disponível em:

$<$ http://portaldoprofessor.mec.gov.br/storage/recursos/9712/geometria/index.htm>. Acesso em:
} 
LOPES, V. Análise de uma objeto de aprendizagem na perspectiva da teoria da aprendizagem significativa: o professor diante da possibilidade de transformação

associando o que está sendo estudado na sala de aula com o seu cotidiano; as imagens em movimento geram interesse na resolução das questões; o desafio colocado para separação dos poliedros de acordo com suas características provoca desejo para analisar e acertar. Sobre a condição de ser um material potencialmente significativo, os professores destacaram que o OA oferece condições para a promoção da aprendizagem não somente de Geometria Espacial, mas inclusive de Geometria Plana, trabalhando ponto, reta e plano de forma mais prática, a partir dos sólidos geométricos, o que demonstra a característica de reutilização do $\mathrm{OA}$ - um mesmo recurso utilizado para objetivos diferentes.

Também analisamos se o OA possuía os recursos facilitadores da promoção da aprendizagem significativa, como a linguagem, o dia a dia e os organizadores prévios. A respeito da linguagem, destacou-se que o OA trabalha com a codificação dual - linguagem escrita (instrução) e visual (figuras em movimento) - importante para negociação e construção de significados. A terceira atividade, como é uma proposta de trabalho em grupo, também evidencia o recurso da linguagem ao possibilitar a interação entre os envolvidos no processo de construção do conhecimento: os alunos, o professor e o OA. Sobre a inclusão de questões do dia a dia, os professores disseram ser indiscutível e já comentado na análise sobre o conhecimento prévio, pois, principalmente nas atividades 1 e 3 , utilizam-se imagens de cidades, o que faz uma ponte entre a realidade do aluno e o conhecimento científico a ser construído. Trabalha-se com organizador prévio, porque a atividade inicial sobre a percepção de figuras geométricas no contexto da cidade permitirá ao aluno, quando for manipular o OA, lembrar-se de coisas que ele já conhece/sabe, acessar conhecimentos que ele já possui sobre Geometria Espacial, sejam eles adquiridos na escola ou fora dela, ajudando-o a relacionar o conhecimento que já possui com o novo conhecimento a ser aprendido.

Nessa análise, evidenciamos que a atividade do OA procurou partir do exercício para a conceituação, do vivencial para o intelectual. Neste sentido, o aluno, quando for manipular o OA, primeiramente analisará os poliedros, suas características, semelhanças e diferenças, para agrupá-los, e depois conhecerá o nome deles, ou seja, conceituará. Essa atividade remete ao processo de reconciliação integrativa da TAS, sendo um exemplo de trabalho para o desenvolvimento da autonomia do aluno e de oportunidade de construção de seu próprio conhecimento; a qual é contrária à forma como estamos acostumados a trabalhar.

Uma questão importante levantada no momento de discussão, pela professora $\mathrm{P}_{57}$, foi a necessidade de se trabalhar conceitos sobre a Geometria Espacial, na sala de aula, antes da atividade com o OA Geometria da Cidade: 
LOPES, V. Análise de uma objeto de aprendizagem na perspectiva da teoria da aprendizagem significativa: o professor diante da possibilidade de transformação

Se formos para a sala de informática, sem trabalhar antes os conceitos, eles não vão entender nada. Então, se você já trabalhou o conteúdo, eu acho que é válido. Mas, você tem que trabalhar antes. Eu acho que o material dá condição para que o aluno relacione uma coisa que você já falou em sala para ele aplicar agora no laboratório. (PROFESSORA $\mathrm{P}_{57}$ )

A partir desse comentário, posicionando o professor diante da possibilidade de transformação, a pesquisadora sugeriu que esse OA fosse trabalhado também na introdução do conteúdo de Geometria Espacial, e não somente após esta. Tal sugestão foi colocada pela pesquisadora para análise do grupo de professores:

\begin{abstract}
Vocês acreditam que esta atividade pode ajudar os alunos a testar, comparar, classificar, e construir o seu conhecimento sobre o assunto? Por exemplo, o exercício 2 sobre anti-prisma, talvez você nunca ouviu falar ou nem lembrava o que é antiprisma. Por meio do teste, da comparação e da classificação, você descobriu o que é anti-prisma, e ninguém te falou o que é. Foi a sua ação diante da atividade que fez você chegar ao conceito. No final da atividade, é que você viu que aquelas figuras que têm certas características são denominadas anti-prismas. (PESQUISADORA)
\end{abstract}

Após a reflexão, a professora $\mathrm{P}_{57}$, que levantou o questionamento inicial, afirmou que:

Pensando bem, quando a gente trabalha com esses OA's, a princípio temos de deixar o aluno sem nenhuma instrução, deixá-lo mexer, manipular e descobrir por si só. Aí ele vai visualizar e analisar. Depois, eu acho que a gente pode introduzir o conteúdo. Dessa forma dá pra fazer. Depois, você volta pra sala, e continua.

A pesquisadora complementou:

Se ficarmos só com o OA, a aprendizagem fica difícil de acontecer. É necessário o antes, o durante e o depois. Acredito que desta maneira, seria uma forma até mais instigante de começarmos um conteúdo. O OA pode ser pra revisar, exercitar, praticar, mas também pra construir o conhecimento.

A professora $\mathrm{P}_{50}$ considerou que utilizar o OA para construir o conhecimento, poderia dificultar a aprendizagem, pois o OA possui muitas figuras. Então ela sugeriu: "Se, por exemplo, você separar dois tipos de figuras, podendo ter até muitas, mas só dois tipos, ficaria mais fácil pra ele classificar. Pra introduzir um conteúdo, precisava ser algo mais simples, pra depois ir aprofundando". Para complementar, a pesquisadora afirmou: "Pra utilizar esse OA, então, podíamos até trabalhar com uma atividade na sala de aula semelhante a do OA, mas com um número menor de tipos de sólidos".

A professora $\mathrm{P}_{8}$ expôs sua opinião: "Se eu fosse trabalhar com esse OA, eu levaria os alunos para o laboratório sem falar nada e pedia que levassem papel e lápis para anotar as 
LOPES, V. Análise de uma objeto de aprendizagem na perspectiva da teoria da aprendizagem significativa: o professor diante da possibilidade de transformação

características que eles estão vendo. Depois, voltaríamos pra sala pra introduzir o conteúdo com base nas anotações que fizeram".

Por meio dessa descrição, vimos que os professores analisaram o OA na perspectiva da Teoria da Aprendizagem Significativa, destacando as potencialidades dessa tecnologia para promover as condições de ocorrência e os recursos facilitadores da aprendizagem significativa. Mesmo reconhecendo a importância do OA relacionado a TAS, alguns docentes, quando confrontados com uma proposta de trabalho, baseada na ressonância entre uma teoria de aprendizagem e uma tecnologia, diferente daquelas que estão acostumados diariamente a praticar, se posicionaram afirmando que da "nova maneira" seria complicado, pois era necessária, primeiramente, a atuação do professor como dono e transmissor do saber, para que depois, no OA, os alunos reproduzissem ou aplicassem a informação transmitida em sala. Essa postura aponta indícios da resistência docente diante da possibilidade de transformação. Em contrapartida, o depoimento da professora $\mathrm{P}_{8}$ aponta indícios de uma possível postura de transformação, afirmando que o OA poderia ser utilizado para introduzir o conteúdo, sem necessidade de uma explanação anterior do professor.

Essa foi a primeira atividade de análise de um OA realizada durante o processo de formação, que posicionou o professor diante de uma possibilidade de transformação e o levou a iniciar um processo de reflexão sobre qual decisão tomar. Tal foi a importância desse momento para o desenvolvimento das próximas atividades, que apontou quais deveriam ser os aspectos trabalhados nos demais encontros.

Percebemos, nos registros feitos pelos professores, uma dificuldade de romper com a estrutura metodológica de "ensino tradicional", na qual primeiramente o professor explica, fala, transmite a informação, para depois o aluno aplicar o que recebeu. Essa questão ficou nítida nos comentários de alguns professores: usaríamos o OA "depois de ter uma aula expositiva e resolução de atividades", que são representativos das "práticas que, embora tenham uma roupagem inovadora, ainda estão enraizadas em um paradigma tradicional” (BOVO, 2004, p. 117). Nessa realidade, identificamos a premência de o professor refletir sobre sua prática pedagógica, a aprendizagem dos alunos e o papel do computador nos processos de ensino e aprendizagem - questões que abordamos nos próximos encontros e atividades.

A partir da atividade de análise do OA "Geometria da Cidade" e diante do contexto apresentado, sugerimos aos professores o desafio de, baseados nos conhecimentos adquiridos, romper com a estrutura metodológica do ensino tradicional. Para isso, vivenciamos outros momentos de análises e debates que possibilitaram aos docentes refletirem sobre novas formas 
LOPES, V. Análise de uma objeto de aprendizagem na perspectiva da teoria da aprendizagem significativa: o professor diante da possibilidade de transformação

de trabalho, mostrando-se passíveis ou não à transformação diante de uma possibilidade de mudança.

Tendo como detonadora essa primeira atividade de análise, iniciou-se a formação de grupos de docentes que se mostraram mais ou menos propícios às mudanças, e os indícios de transformação foram se evidenciando no desenvolver do processo de formação continuada.

O grupo de professores que, diante da possibilidade de transformação, apontou indícios de uma natureza propícia às mudanças, é menor em relação ao grupo que aderiu a utilização das TICE's. Entretanto, houve transformações nas concepções de alguns docentes em relação a ensinar de uma maneira que desafie a tradição da matemática escolar, ficando explícitas essas mudanças no grupo de cinco professoras, as quais denominamos protagonistas. Percebemos essas protagonistas na descrição que Ferreira (2003) faz dos professores que se mostram "mais propícios a mudanças significativas e duradouras". Segundo a pesquisadora, esses professores são comprometidos com o trabalho, abertos à mudança, sentem-se desafiados, percebem certa contradição entre seus objetivos e práticas e o novo saber. Caracterizam-se também como sendo as docentes que incorporaram uma maneira diferente de ensinar Matemática com base numa teoria de aprendizagem, de conduzir suas aulas, de encarar e de estar na profissão.

Podemos perceber, nos relatos das protagonistas, que a inserção das tecnologias da informática nas aulas de Matemática, “[...] não se trata apenas de um novo recurso a ser incorporado à sala de aula, mas de uma verdadeira transformação, que transcende até mesmo os espaços físicos em que ocorre a educação” (KENSKI, 2007, p. 47), alterando o espaço das aulas, que passou a abranger também o laboratório de informática.

A vivência de novas experiências didáticas a partir de inovações metodológicas, e a reflexão permanente e sistemática antes, durante e após as experiências experimentadas por essas protagonistas, fizeram com que essas docentes, diante da possibilidade de transformação, iniciassem um processo de mudança de sua prática pedagógica. Por conseguinte, para essas docentes, a formação continuada foi um caminho que abriu portas para aprender, adaptar, romper barreiras e desafios; o que torna o seu perfil mais consentâneo às exigências da sociedade da informação e à necessidade de formação dos alunos dessa nova era; adequação que contribui para a melhoria dos processos de ensino e aprendizagem da Matemática.

Dessa maneira, a postura dessas docentes, diante da possibilidade de transformação, se caracteriza por uma prática interrogativa, questionadora, investigativa, exploratória, que possibilita uma transição do ensinar para o "aprender a aprender", criando situações em que o aluno possa construir o seu conhecimento a partir de seus erros e acertos, tentativas, 
LOPES, V. Análise de uma objeto de aprendizagem na perspectiva da teoria da aprendizagem significativa: o professor diante da possibilidade de transformação

comparações, conjecturas e conclusões. Assim, o professor se torna um mediador e avança para a zona de risco por meio de seu trabalho com as TICE's.

\section{CONCLUSÃO}

No processo de formação continuada, buscamos posicionar os professores diante da possibilidade de transformação, levando-os a refletir sobre sua prática pedagógica e a necessidade de mudança. No decorrer do caminho, percebemos indícios de transformação em alguns docentes, enquanto em outros não. Talvez esses últimos não tenham apresentado durante os momentos da formação continuada tais indícios de transformação; ou não os percebemos; ou ainda, os professores não notaram diferenças entre a proposta de uso dos OA's e aquilo que eles fazem em suas práticas; ou suas concepções sobre "ensinar matemática" permaneceram intocáveis, mesmo passando por esse processo de formação.

Nessas possibilidades de transformação, não identificamos nenhuma resistência profissional quanto à inserção das novas tecnologias na sala de aula; pelo contrário, os professores decidiram participar da formação em busca de aprender a utilizar esses novos recursos em suas aulas e utilizaram. Soubemos do uso dos OA's nos relatos feitos na plataforma, nos encontros presenciais, por e-mail e pessoalmente. Os docentes participantes perceberam que, com a chegada dos computadores na sociedade em geral e nas escolas, a utilização desses recursos torna-se irreversível.

Porém, percebemos na postura de alguns professores, diante da possibilidade de transformação, resistências na incorporação de uma maneira diferente de ensinar Matemática baseada numa teoria de aprendizagem: uma dificuldade de transformar a maneira de conduzir suas aulas, de alterar a ordem de suas ações que se repetem ano após ano da mesma forma. $\mathrm{O}$ fato de muitos professores terem usado OA's em suas aulas, mas não terem registrado o planejamento feito, a análise do OA segundo a TAS, as reflexões das ações realizadas, bem como socializado essa experiência - aspectos que direcionam para uma nova postura pedagógica -, aponta indícios da resistência docente nesse âmbito.

Conforme descritas na atividade realizada, essas concepções de utilização do OA, “depois de ter uma aula expositiva e resolução de atividades", como sugeriu professora a $\mathrm{P}_{57}$, evidenciam a dificuldade do professor em romper com a estrutura metodológica do ensino tradicional, na qual o professor explica a matéria, e dá exemplo, e o aluno exercita o conhecimento recebido por meio das atividades. Segundo essas visões, o OA pode ser um 
LOPES, V. Análise de uma objeto de aprendizagem na perspectiva da teoria da aprendizagem significativa: o professor diante da possibilidade de transformação

instrumento somente para exercitar o conteúdo transmitido, e não para auxiliar o aluno na construção de seu próprio conhecimento.

Dessa maneira, a postura desse professor, diante da possibilidade de transformação, se caracteriza pela permanência na reproduzir o conhecimento, em "empurrar a informação". Assim, o docente continua sendo o dono do saber, responsável por compartilhar o que sabe com seus alunos. Com essas ações, o professor assume um trabalho com a TICE's que se restringe na mera aplicação de uma nova técnica de ensino, situando-se na zona de conforto, e sentindose, dessa maneira, inseguro para assumir a zona de risco.

Existiram mudanças com a incorporação de uma maneira diferente de ensinar Matemática baseada em uma teoria de aprendizagem, na forma de conduzir as aulas, de encarar e de estar na profissão, porém mais pontuais e menos profundas quando comparadas com as relacionadas à incorporação das tecnologias. Esse fato demonstra a limitação da formação continuada que, sozinha, não consegue romper com certos paradigmas, necessitando do envolvimento de outros elementos de todo um contexto.

Reiteramos que mudar não consiste em uma simples decisão, pois mudanças acontecem em um processo difícil, lento e penoso. Mudar não significa alterar o método, se a postura pedagógica continua a mesma. Mudar exige a adoção de uma pedagogia que sustente as ações transformadas.

Frente aos problemas encontrados e às contribuições obtidas, alcançamos, para um grupo de professores, o patamar que desejávamos: os desafios propostos pelo paradigma emergente foram superados, pois ao refletirem sobre a ação docente, iniciaram um trabalho com seus alunos adotando uma postura diferenciada, ultrapassando barreiras antes consideradas intransponíveis, utilizando boas metodologias tecnológicas, oferecendo aos educandos aprendizagens para toda a vida e atendendo às demandas da sociedade da informação; potencializou-se a atividade desses professores de Matemática com o uso das TICE's; os caminhos desses profissionais foi transformado e refeito, e eventuais concepções pedagógicas retrógadas, rompidas; as práticas de sala de aula foram reavaliadas e moldadas como parte integrante de suas novas identidades pessoais de professores; agora se veem como novos sujeitos, únicos e singulares, modificados, como caracteriza Bairral (2005, p. 51): “[...] agentes potencialmente ativos e comprometidos em mudar situações $[\ldots .$.$] ".$

Logo, concluímos que diante da possibilidade de mudança, a Educação precisa ser sempre questionada e reelaborada, visto que o exercício de se adaptar às formas de ensinar e de aprender e às inovações é contínuo e nunca terá fim. Nesse viés, o professor precisa se enveredar 
LOPES, V. Análise de uma objeto de aprendizagem na perspectiva da teoria da aprendizagem significativa: o professor diante da possibilidade de transformação

continuamente em processos de formação continuada, a fim de discernir as contribuições dessas transformações para a sua formação e prática pedagógica, tendo como base aspectos teóricos e metodológicos.

Assim, terminamos esse artigo concluindo - a partir da análise apresentada - que os OA's na perspectiva da TAS abrem possibilidades para os docentes se renderem à transformação de seus conhecimentos e de sua prática pedagógica e de se desenvolverem profissionalmente.

\section{REFERÊNCIAS}

AUSUBEL, D. P. Aquisição e retenção de conhecimentos: uma perspectiva cognitiva. Lisboa: Plátano, 2003.

BAIRRAL, M. A. Desenvolvendo-se criticamente em matemática: a formação continuada em ambientes virtualizados. In: FIORENTINI, D.; NACARATO, A. M. (Org). Cultura, formação e desenvolvimento profissional de professores que ensinam Matemática: investigando e teorizando a partir da prática. São Paulo: Musa Editora, 2005. p. 49-67.

BALDINO, R. R. Pesquisa-ação para a formação de professores: leitura sintomal de relatórios. In: BICUDO, M. A. V. (Org.). Pesquisas em Educação matemática: concepções \& perspectivas. São Paulo: UNESP, 1999. p. 221-245.

BOGDAN, R. C.; BIKLEN, S. K. Investigação qualitativa em educação: uma introdução à teoria e aos métodos. Porto: Porto Editora, 1994.

BORBA, M. C.; PENTEADO, M. G. Informática e educação matemática. Belo Horizonte: Autêntica, 2010.

BOVO, A. A. Formação continuada de professores de matemática para o uso da informática na escola: tensões entre proposta e implementação. 2004. 358 f. Dissertação (Mestrado em Educação Matemática) - Universidade Estadual Paulista (UNESP), Rio Claro, 2004.

DOMENICO, L. C.; RAMOS, A. F.; TORRES, P. L. Uma experiência com objetos de aprendizagem no ensino de Matemática. UNIrevista, v. 1, n. 2, abr. 2006.

FERREIRA, A. C. Metacognição e desenvolvimento profissional de professores de Matemática: uma experiência de trabalho colaborativo. 2003. 390 f. Tese (Doutorado em Educação Matemática) - Universidade Estadual de Campinas, Campinas, 2003. 
LOPES, V. Análise de uma objeto de aprendizagem na perspectiva da teoria da aprendizagem significativa: o professor diante da possibilidade de transformação

GUÉRIOS, E. Espaços intersticiais na formação docente: indicativos para a formação continuada de professores que ensinam matemática. In: FIORENTINI, D.; NACARATO, A. M. (Org). Cultura, formação e desenvolvimento profissional de professores que ensinam Matemática: investigando e teorizando a partir da prática. São Paulo: Musa Editora, 2005. p. 152-174.

KENSKI, V. M. Educação e tecnologias: o novo ritmo da informação. São Paulo: Papirus, 2007.

MACHADO, E. C.; SÁ FILHO, C. S. O computador como agente transformador da educação e o papel do objeto de aprendizagem, 2003. Disponível em: < www.abed.org.br/seminario2003/texto11.htm>. Acesso em: 28 mar. 2011.

MASETTO, M. T. Mediação pedagógica e o uso da tecnologia. In.: BEHRENS, M. A.; MASETTO, M. T.; MORAN, J. M. Novas tecnologias e mediação pedagógica. São Paulo: Papirus, 2000. p. 113-173.

MASINI, E. F. S.; MOREIRA, M. A. Aprendizagem significativa: condições para ocorrência e lacunas que levam a comprometimentos. 1. ed. São Paulo: Vetor, 2008.

PONTE, J. P.; SERRAZINA, L. Práticas profissionais dos professores de Matemática. Quadrantre, Lisboa, v. 13, n. 2, p. 51-74, 2004.

VALENTE, J. A. Computadores e conhecimento: repensando a educação. São Paulo: UNICAMP, 1999.

WILEY, D. A. Connecting learning objects to instructional design theory: a definition, a metaphor, and a taxonomy. In WILEY, D. A. (Org.) The instructional use of learning objects: Online Version, 2000. Disponível em:

$<$ http://reusability.org./read/chapters/wiley.doc>. Acesso em: abr. 2011.

Recebido em: 20/10/2014

Aprovado em: 28/01/2015

Publicado em: 29/06/2015 